\title{
Interdisziplinäre Untersuchungen zum altorientalischen Bierbrauen in der Siedlung von Tall Bazi/Nordsyrien vor rund 3200 Jahren
}

\author{
von Martin Zarnkow, Elmar Spieleder, Werner Back, Bertram Sacher, \\ Adelheid Otto und Berthold Einwag
}

\section{Überblick}

Im September 2004 und April 2005 fanden sich auf Einladung der Grabungsleiter Brauereitechnologen in der archäologischen Grabung von Tall Bazi in Syrien ein, um gemeinsam auf experimentellen Wegen der antiken Malzund Bierbereitung nachzugehen. Die Ausgrabung bot bemerkenswerterweise einen fast unberührten Fundhorizont der späten Bronzezeit (13. Jahrhundert v. Chr.), der in der so genannten Weststadt von Tall Bazi weitgehend alle Gegenstände des täglichen Lebens wiedergab. Unter anderem wurden in den sich ähnelnden Häusern immer wieder die gleichen großen, fassförmigen Gefäße gefunden. Zahlreiche nasschemische und mikroskopische Untersuchungen am Lehrstuhl für Technologie der Brauerei I der Technischen Universität München ergaben Hinweise auf einen möglichen Verwendungszweck der Gefäße zum Bierbrauen. Unter anderem konnten Oxalat und Hefen nachgewiesen werden. In weiteren Versuchsreihen wurde eindeutig dargelegt, dass Malz, also künstlich zum Keimen gebrachtes Getreide, auch in der Bronzezeit ein zwangsläufiger Bestandteil bei der Bierbereitung war. Unter zusätzlicher Berücksichtigung der botanischen und klimatischen Gegebenheiten vor Ort wurde ein Mälzungs- und Bierbereitungsregime aufgestellt, welches bestechend einfach (ein Kaltmaischverfahren) war und als Basisbierbereitung angesehen werden kann. Darauf aufbauend ist es durchaus denkbar, dass in der Bronzezeit eine kompliziertere Technologie angewandt werden konnte oder auch andere Rohstoffe zum Einsatz kamen.

\begin{abstract}
In September 2004 and April 2005 the excavators of Tall Bazi in Syria invited brewing technologists to join their team at Tall Bazi, in order to reproduce the ancient malt and beer production methods together. The excavation of the so called Weststadt of Tall Bazi offers exceptionally well preserved occupation levels of the Late Bronze Age (13 ${ }^{\text {th }}$ century B.C.), where all the equipment of the daily life was, to a large extent, still found in situ. Among other finds, similar large, barrel-shaped vessels were found in the same place within 30 houses. Numerous wet-chemical and microscopic examinations at the Lehr-
\end{abstract}


stuhl für Technologie der Brauerei I of the Technische Universität München gave indications of the possible purpose of the vessels. Among other things, oxalate and yeast could be identified. In further test series it was clearly established that malt, a grain artificially brought to germination, was present and was thus a necessary ingredient for the production of beer in the Bronze Age. With additional consideration of the local botanical and climatic circumstances a malting and beer production strategy was set up, which was impressively simple (a cold mashing method) and can be proposed as the first stage of the beer production. After this, it is quite probable that a more complex technology was applied and also additional raw materials were used.

\section{Einleitung}

Im Gilgamesch-Epos, einer der ersten großen Dichtungen der Welt, verkörpert Enkidu den Freund und Gegenspieler von Gilgamesch. Zunächst ein wildes, tierähnliches Wesen wird er zum Menschen zum einen durch die Begegnung mit einer Frau und zum anderen durch den Genuss von Brot und Bier. In der zweiten Tafel des Gilgamesch-Epos heißt es: „Brot aß Enkidu, bis er gesättigt war, trank den Rauschtrank - der Krüge sieben. Frei ward sein Inneres und heiter, es frohlockte sein Herz, und sein Antlitz erstrahlte. Mit Wasser wusch er ab seinen haarigen Leib, er salbte sich mit Öl und ward

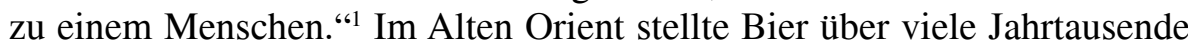
(wohl abgesehen von Wasser) das geläufigste Getränk dar. Sicher belegt ist der Genuss von Bier seit Erfindung der Schrift in Mesopotamien um $3000 \mathrm{v}$. Chr. Unter den ersten, noch bildhaften Schriftzeichen der Menschheit findet sich das Zeichen für Bier in Form eines gefüllten Kruges. ${ }^{2}$ Wahrscheinlich geht der Biergenuss in Mesopotamien aber viel weiter zurück, möglicherweise bis zu dem Moment im präkeramischen Neolithikum vor ca. 11.000 Jahren, als im heutigen Nordirak und Nordsyrien die Gerste - Grundstoff der Bierbereitung - kultiviert wurde; ${ }^{3}$ eine wesentliche kulturelle Errungenschaft, die erst Jahrhunderte später zusammen mit dem Bier auch den Okzident er-

1 Das Gilgamesch-Epos. Neu übersetzt und mit Anmerkungen versehen von Albert Schott, ergänzt und teilweise neu gestaltet von Wolfram von Soden, Stuttgart 1958/1974. In der neuassyrischen Version des Gilgamesch-Epos, die kürzlich in der meisterhaften Übersetzung von Stefan M. Maul erschien, ist der Passus teilweise beschädigt, siehe Das Gilgamesch-Epos. Neu übersetzt und kommentiert von Stefan M. Maul, München 2005, S. 59f.

2 Margaret W. Green u. Hans J. Nissen, Zeichenliste der archaischen Texte aus Uruk, in: Ausgrabungen der Deutschen Forschungsgemeinschaft in Uruk-Warka 11, 1987, S. 229f., Zeichen 286: KAS; Hans J. Nissen, Peter Damerow u. Robert K. Englund, Frühe Schrift und Techniken der Wirtschaftsverwaltung im alten Vorderen Orient. Informationsspeicherung und -verarbeitung vor 5000 Jahren, Bad Salzdetfurth 1991, S. 2.

3 Mark Nesbitt, When and Where Did Domesticated Cereals First Occur in Southwest Asia? In: René T.J. Cappers u. Sytze Bottema (Hg.), The Dawn of Farming in the Near East. Studies in Early Near Eastern Production, Subsistence, and Environment 6, 2002, S. 113132. 
reichte. Wie wir aus Tausenden von Keilschrifttexten wissen, ${ }^{4}$ gehörte Bier zu den „Hauptnahrungsmitteln“. Es beugte einerseits durch seinen hohen Gehalt an Nährstoffen, Vitaminen und Aminosäuren der Mangelernährung vor, andererseits trug es weniger pathogene Keime als das vielerorts verfügbare Trinkwasser. Der Mangel an Sauerstoff und der niedrige $\mathrm{pH}$-Wert bewirken einen weitgehenden Schutz des Bieres vor mikrobiellem Verderb. ${ }^{5}$

Biergenuss spielte eine tragende Rolle im privaten und öffentlichen Leben. Dementsprechend wurde Bier sowohl im großen Maßstab für den öffentlichen Bedarf produziert (der tägliche Konsum eines Palastes betrug viele Hektoliter), als auch privat von jedem Haushalt. Wie heute noch in abgelegenen Regionen Afrikas, war es Aufgabe der Frauen, regelmäßig Bier für den Haushalt zu brauen. Doch wie ist es möglich, dass ein alkoholhaltiges Getränk im überwiegend warmen Klima Vorderasiens über Jahrtausende das Standardgetränk nicht nur für Männer, sondern auch für Frauen und Kinder darstellte? Und: müsste man nicht Spuren davon im archäologischen Befund der unzähligen antiken Stätten finden, die seit etwa 200 Jahren im Vorderen Orient ausgegraben wurden?

\section{Neue archäologische Hinweise auf antikes Bierbrauen: Der Fall Tall Bazi}

Bislang wurde kaum der Versuch gemacht, archäologische Belege für das Bierbrauen in Mesopotamien zu suchen. Die einzige, angeblich eindeutig identifizierbare „Bierbrauerei“ wurde im „Tablet Building“ in Hadidi gefunden. ${ }^{6}$ Im Licht der hier vorgelegten neuen Erkenntnisse darf sie aber wohl eher als gewöhnliches Wohnhaus gedeutet werden, in dem unter anderem auch Bier gebraut wurde.

Jüngste Ausgrabungen förderten nämlich in Nordsyrien einen Ort zu Tage, an dem sich das antike Brauwesen nun auch an den archäologischen Relikten festmachen lässt: Tall Bazi, etwa $60 \mathrm{~km}$ südlich der Grenze zur Türkei am Ostufer des seit 1999 gefluteten Tishreen-Stausees (siehe Abb. 1). Die auf einem 60 m hohen Ausläufer des Euphratrandgebirges gelegene Zitadelle überragt heute den See, während die auf der unteren Flussterrasse gelegene Unterstadt inzwischen größtenteils überschwemmt ist. Die Ausgrabun-

4 Die Literatur zu Bier anhand von Keilschriftquellen ist schier unerschöpflich. Gute Zusammenfassungen finden sich bei Robert I. Curtis, Ancient Food Technology, Leiden 2001; Lucio Milano (Hg.), Drinking in Ancient Societies, History of the Ancient Near East/Studies 6, Padova 1994.

5 Werner Back, Farbatlas und Handbuch der Getränkebiologie, Nürnberg 1994, S. 16.

6 Marie-Henriette Gates, Dialogues between Ancient Near Eastern Texts and the Archaeological Record. Test Cases from Bronze Age Syria, in: Bulletin of the American Society of Oriental Research 270, 1988, S. 66ff.; Curtis (wie Anm. 4), S. 214. Eine kürzlich in Anatolien zutage getretene Brauerei ist aufgrund der andersartigen materiellen Relikte für die Interpretation der Grabungsbefunde in Mesopotamien nur bedingt hilfreich. Vgl. Vuslat Müller-Karpe, Bier und Bierproduktion in Anatolien zur Bronzezeit, in: Ünsal Yalcin (Hg.), Das Schiff von Uluburum, Bochum 2005, S. 171-184. 


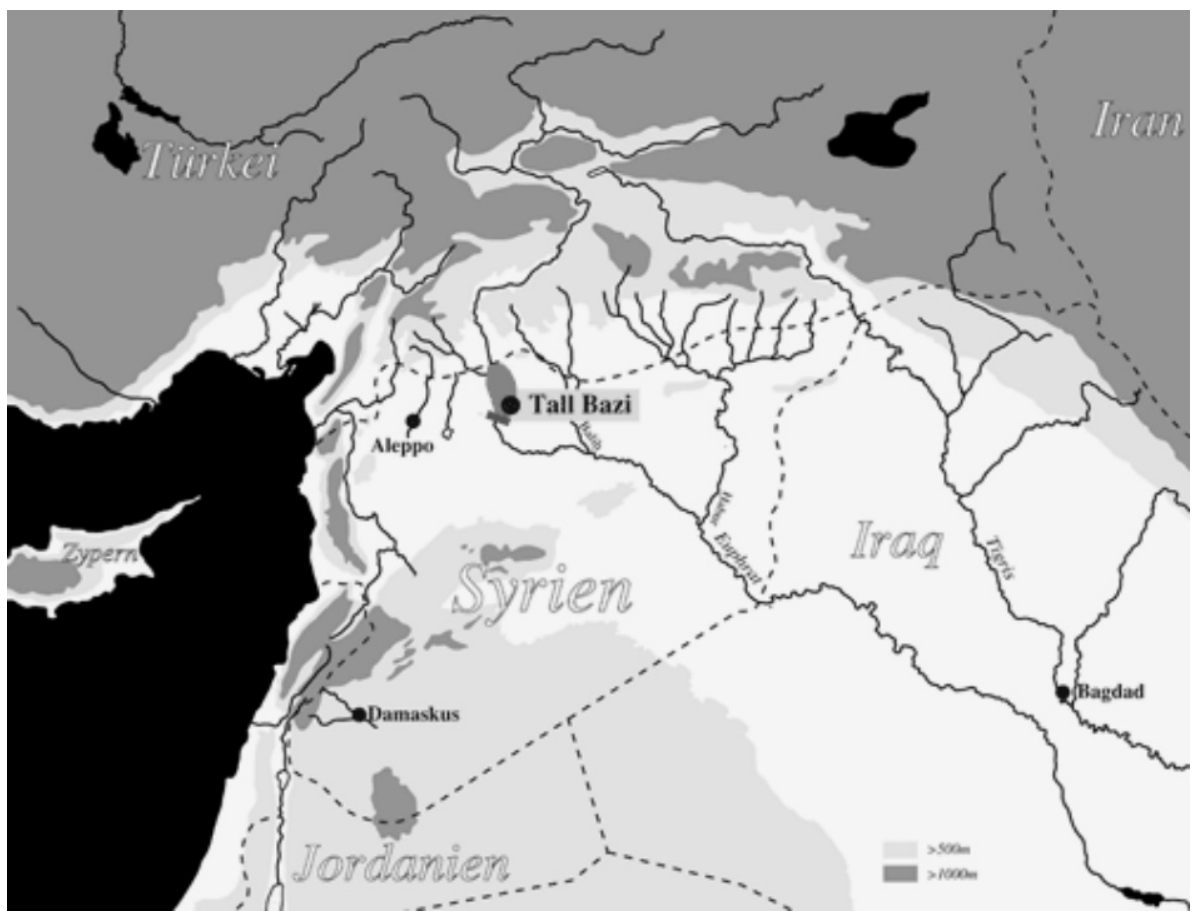

Abb. 1: Die Ausgrabungsstätte Tall Bazi in Nordsyrien.

gen konzentrierten sich von 1993 bis 1999 auf die westliche Unterstadt (,Weststadt"), die großflächig freigelegt wurde. Es handelte sich hierbei um eine im 13. Jahrhundert v. Chr. geplant angelegte Siedlungserweiterung rein städtischen Charakters, deren etwa 50 ausgegrabene Häuser einerseits dem Wohnen, andererseits der handwerklichen Produktion dienten. Ein in der Mitte der Häuserviertel gelegener Platz bildete das ökonomische Zentrum der Weststadt. $^{7}$

Die Einrichtung der Häuser war noch weitgehend erhalten, weil das Ende offenbar sehr schnell über die Bewohner hereingebrochen war. In nahezu jedem Haus wurde zumeist an der gleichen Stelle ein großes, tonnenförmiges Gefäß gefunden. Es stellte das größte Gefäß des Hauses dar, hatte eine weite Mündung, war stets in den Boden eingelassen und häufig ringsum eingemauert, also immobil und nur schwer zu reinigen. Da in den Gefäßen (anders als in vielen großen Vorratsbehältern) nie verkohltes Getreide gefunden wurde,

7 Das Projekt begann als Unternehmung des Deutschen Archäologischen Instituts (DAI) Damaskus, seit 2000 ist es ein DFG-gefördertes Projekt der Ludwig-Maximilian-Universität München. Die Leitung liegt in Händen von Berthold Einwag und Adelheid Otto. Für die letzten Ausgrabungsberichte vgl. u. a. dies., Tall Bazi 1998 und 1999. - Die letzten Untersuchungen in der Weststadt, in: Damaszener Mitteilungen 13, 2002, S. 65=88; dies., Wettlauf mit der Zeit, in: Welt und Umwelt der Bibel 1, 2004, S. 64-69. 
hingegen oftmals ein weißlicher Belag vorhanden war, müssen sie zur Aufnahme von Flüssiggütern gedient haben. Die einzigen anderen, damals in größeren Mengen genossenen Flüssigkeiten (Milch, Öl und Wein) kommen wegen der oben genannten Eigenschaften des Gefäßes kaum in Frage. Die Aufbewahrung von großen Mengen Wasser an einem Ort in unmittelbarer Flussnähe ist ebenfalls auszuschließen, zumal durch das Einmauern der Kühlungseffekt durch Verdunstungskälte wegfällt. Bleibt also Bier als Möglichkeit. Doch lässt sich ein Zusammenhang zwischen diesem Gefäß und Bier nachweisen?

\section{Der Beginn der interdisziplinären Forschung zwischen Archäologie und Brautechnologie}

Die Archäologen Adelheid Otto und Berthold Einwag wandten sich an Spezialisten des Brauwesens der Technischen Universität München Weihenstephan vom Lehrstuhl für Technologie der Brauerei I und baten um eine naturwissenschaftliche Untersuchung von Scherbenproben der genannten Gefäße. Die Analyse der rund 3200 Jahre alten Gefäßrückstände erbrachte tatsächlich Oxalat-positive Befunde. Der Zusammenhang dieses Gefäßtyps mit Bier war also höchst wahrscheinlich; doch zu welchen Vorgängen hatte es gedient? Die Tatsache, dass sich in vielen Häusern neben dem großen Gefäß ein weitmundiges Behältnis mit Lochboden und oft ein bis zwei Vorratsgefäße, die zur Getreideaufbewahrung dienten, fanden, deutete auf einen Vorgang hin, der verschiedene große Gefäße zu unterschiedlichen Prozessen benötigte, welche offensichtlich guter Belüftung bedurften, also am wahrscheinlichsten auf Bierbrauen. Ob sich diese Vermutung bestätigen lassen würde, wie diese Prozesse unter den damaligen Bedingungen, mit den vorhandenen Rohstoffen und im Klima Vorderasiens ausgesehen haben könnten, wie das Produkt geartet gewesen sein könnte, ließ sich nicht im Labor klären. Hierzu bedurfte es der Versuche vor Ort.

So begann das gemeinsame Projekt zur Rekonstruktion des antiken Bierbrauens im Alten Orient. Im Sommer 2004 und im Frühjahr 2005 machte sich unter oben genannter Fragestellung ein Team von Archäologen und Brautechnologen auf, in Tall Bazi in Nordsyrien durch Versuche dem altorientalischen Bierbrauen auf die Schliche zu kommen.

Die Schritte im antiken Prozess des Bierbrauens kennen wir aus zahlreichen in Keilschrift verfassten Texten, die vom Bierbrauen handeln; allerdings stellen diese Texte keine Rezeptur dar, wie sie sich heutige Wissenschaftler wünschten. Die ausführlichste Quelle ist die Hymne auf die Biergöttin Nin$\mathrm{kasi}^{8}{ }^{8}$ die das Bierbrauen auf gattungsspezifisch lyrische Weise beschreibt.

8 Vgl. Miguel Civil, A Hymn to the Beer Goddess and a Drinking Song, in: Studies Presented to A. Leo Oppenheim, Chicago 1964, S. 67-89; Wolfgang Röllig, Das Bier im Alten Mesopotamien, Berlin 1970; Marten Stol, Zur altmesopotamischen Bierbereitung, in: Bibliotheca Orientalis 28, 1971, S. 167-171. 
Weitere Quellen sind Wirtschaftstexte, deren Mengenangaben der zum Bierbrauen benötigten Zutaten Hinweise zum Brauprozess liefern. ${ }^{9}$ Welche Zutaten jedoch mit bestimmten Begriffen gemeint sind, wird zurzeit noch diskutiert. Ob sich beispielsweise hinter „,bappir“ eine Art gebackenes Brot verbirgt, oder aber ein loses, schüttbares Getreideprodukt, können zum einen nur weitere philologische Untersuchungen zur Terminologie der Begriffe und zum anderen Experimente vor Ort klären, die den vorherrschenden klimatischen Bedingungen und der Beschränktheit der Energieressourcen Rechnung tragen.

Auch wenn gelegentlich ein möglicher Klimawandel um 1350 v. Chr. in der nordsyrischen Region als denkbare Ursache für die auffallenden Änderungen in der Besiedlungsdichte angenommen wird, ${ }^{10}$ so wird überwiegend davon ausgegangen, dass das damalige Klima (um 1200 v. Chr.) im weitesten Sinne dem heutigen entspricht. ${ }^{11}$ Die Region um Tall Bazi liegt am Rande der Regenfeldbauzone. Die mittleren Temperaturen liegen zwischen $7{ }^{\circ} \mathrm{C}$ im Januar und $33{ }^{\circ} \mathrm{C}$ im Juli, die Jahresniederschläge unterschreiten in trockenen Jahren $100 \mathrm{~mm}$ (Niederschlagmittel etwa $250 \mathrm{ml} / \mathrm{a}$ ).

Die Euphratregion hat heute einen großen Teil seiner Auenwälder eingebüßt und die Bäume, allen voran Pappeln, wurden eher als Bau- denn als Brennholz verwendet. Als Heizmaterial kamen Reisig und Tierdung in Frage. Die paläobotanische Betrachtung der Getreidefunde von Bazi durch Rainder Neef (Berlin) ergab hauptsächlich mehrzeilige Gerste (Hordeum vulgare), ein wenig Nacktweizen (Triticum aestivum oder turgidum) und selten

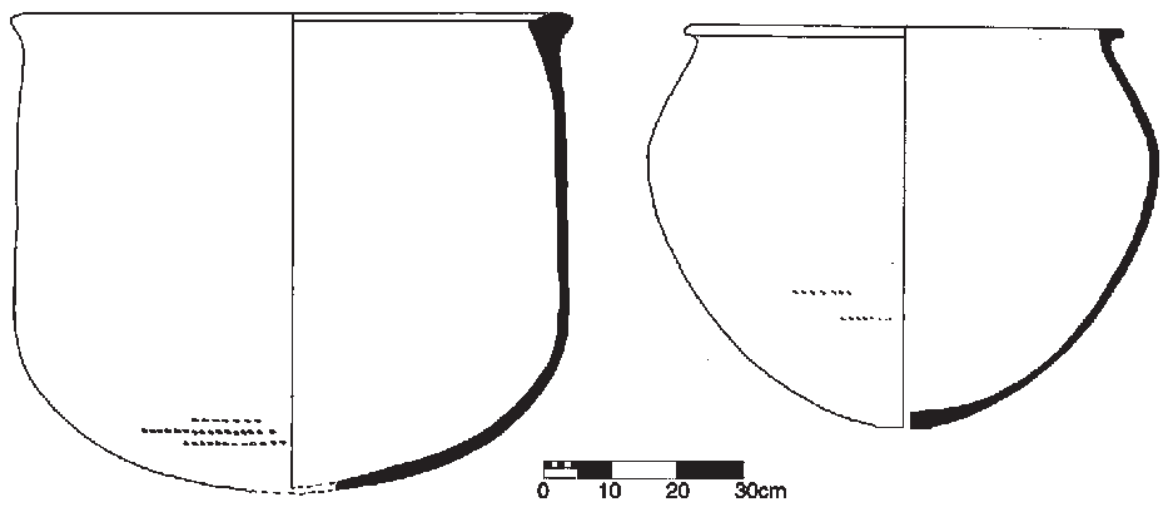

Abb. 2a und 2b: Großes 2001 fassendes „Biergefäß“ und so genanntes Lochbodengefäß mit 90 bis 1101 Volumen.

9 Marvin A. Powell, Metron Ariston: Measure as a Tool for Studying Beer in Ancient Mesopotamia, in: Milano (wie Anm. 4), S. 91-119.

10 http://www.palynologie.uni-goettingen.de/Kirleis.html [Stand: 05.2005].

11 Eugen Wirth, Länderkunde Syrien, Darmstadt 1971, S. 98f. 
Emmer (Triticum dicoccum). An einigen Gerstenkörnern waren deutliche Keimspuren zu erkennen. ${ }^{12}$

\section{Die Fundumstände der fraglichen Gefäße}

Die Siedlung von Bazi wurde gegen 1200 v. Chr. gewaltsam zerstört, großflächig verbrannt und nie mehr wieder bewohnt. So blieb das Inventar, insbesondere die Keramikgefäße, exzellent erhalten. In den insgesamt 50 ausgegrabenen Häusern wurden immer wieder dieselben Sets von Gefäßen aufgefunden, wobei das größte eines Haushalts das oben beschriebene tonnenförmige Gefäß mit bis zu 2001 Fassungsvermögen war (siehe Abb. 2a).

Es war stets an dem am besten belüfteten Platz im Haus in den Boden eingelassen, zumeist nahe dem Eingang und unter der aufs Dach führenden Treppe. In Abbildung 3 ist beispielhaft für die Position eines Biergefäßes Haus Nr. 41 dargestellt, dessen Grundriss, feste Einbauten und mobiles Inventar sich in den anderen Häusern in ähnlicher Weise wiederfinden lassen. Manche Häuser wiesen zusätzlich ein solches Gefäß auf dem Dach oder im zweiten Geschoss auf. In wenigen Fällen (auffälligerweise gerade in den Häusern, die auch geschäftlich bzw. gesellschaftlich genutzt wurden) waren diese Gefäße aus dem Hauptraum ausgelagert, so dass an eine beabsichtigte Auslagerung aufgrund bestimmter störender Eigenschaften geschlossen wird. Ferner gehören zum Standard-Keramik-Set Gefäße mit Lochboden mit einem Fassungsvermögen von etwa 90-110 1 (siehe Abb. 2b).

\begin{tabular}{lccc} 
Gefäß & Fundbezeichnung & Oxalat & Tartrat \\
\hline Biergefäß & $30 / 39: 34$ & + & - \\
Biergefäß & $51 / 23 \mathrm{SW}$ & + - & - \\
großes Lochbodengefäß & $23 / 33: 41$ & + & + \\
großes Lochbodengefäß & $21 / 27: 20$ & + & + \\
Topfflasche & $28 / 33: 6,10$ & + & - \\
mittelgroßer Topf & $25 / 36: 50$ & + & - \\
mittelgroßer Topf & H 22 R53FB & + & + \\
mittelgroßer Topf mit Tülle & $25 / 29: 18,2$ & - & - \\
mittelgroßer Topf mit Tülle & $28 / 33: 6,19$ & - & - \\
großer Krug & H25 R3 & - & - \\
kleine Kleeblattkanne & $23 / 33: 26$ & + & + \\
kleine Kleeblattkanne & $29 / 32: 31,21$ & - & + \\
Kleeblattkanne & $29 / 31: 9,2$ & - & - \\
Napf & $29 / 31: 9,5$ & + - & -
\end{tabular}

Tab. 1: Oxalat- und Tartratbestimmung mittels Tüpfeltests der Fundkeramik (zur Oxalatbestimmung war eine Filtration notwendig, da die anhaftenden Erdteilchen die Farbbeurteilung stark beeinträchtigten).

12 Dies wurde auch vor Ort nochmals von den Brautechnologen und zusätzlich an einigen Mustern von Hans-Peter Stika (Hohenheim) bestätigt. 


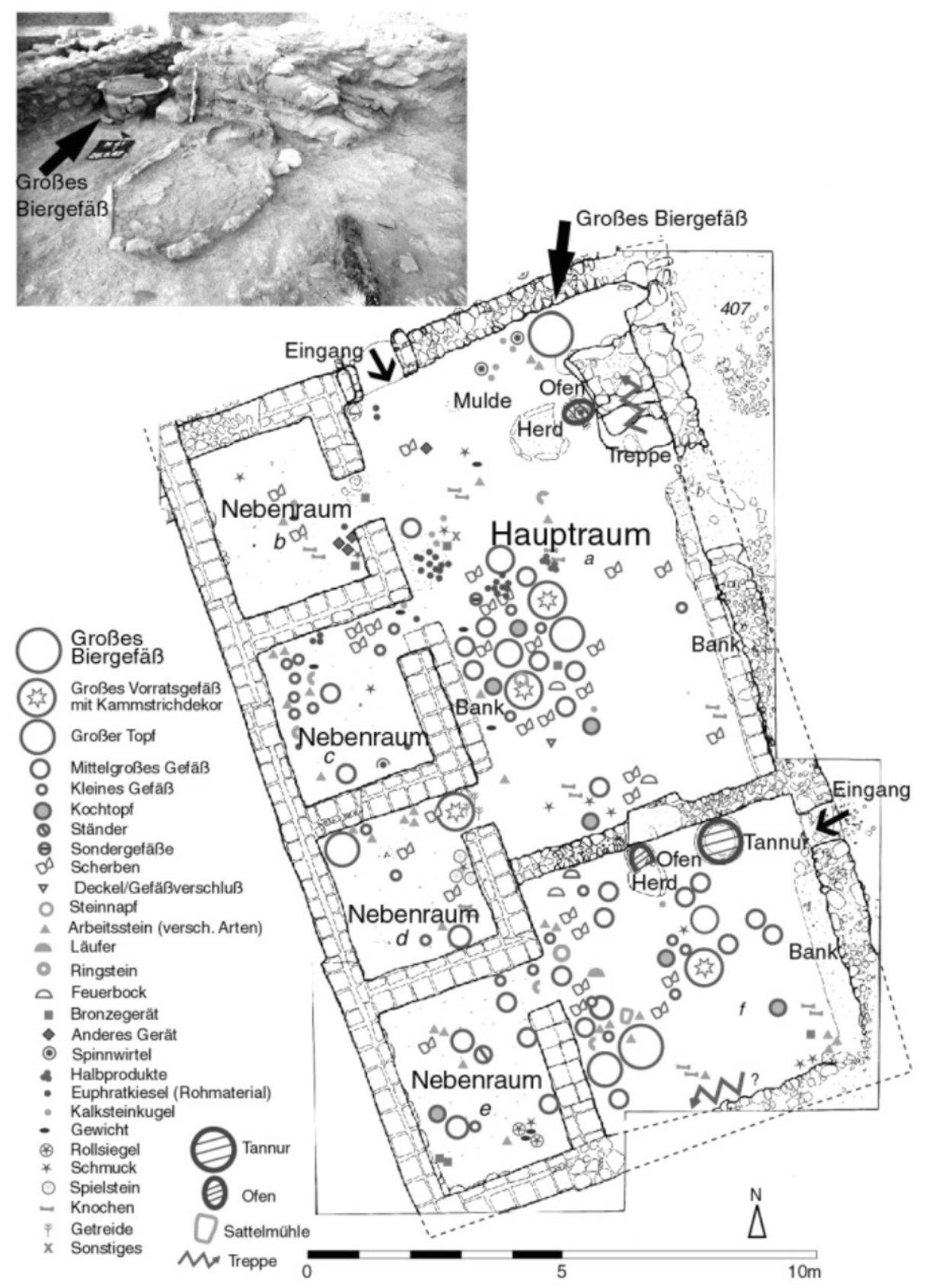

Haus 41 Untergeschoß, Inventar

Abb. 3: Grundriss des Hauses Nr. 41 der Weststadt von Bazi mit den Fundorten der Einrichtungsgegenstände und Keramik. 
Aufschluss für die damalige Verwendung der Gefäße konnten nur chemische Analysen erbringen, die in Form von Tüpfeltests an wenigen ausgewählten Scherben des Bodenbereiches der Gefäße durchgeführt wurden (siehe Tab. 1). ${ }^{13}$ Untersucht wurden Behältnisse, die aufgrund archäologischer Indizien mit Bier in Zusammenhang gestanden haben könnten (neben dem groBen Bier- und Lochbodengefäß auch Topfflaschen, aus denen Bier mittels Saugrohren getrunken wurde) sowie Gefäße, die sonstige Verwendung fanden (Kleeblattkannen als Weingefäße, große Krüge als Aufbewahrungsgefäße für andere Flüssigkeiten, Näpfe als Essschüsselchen usw.).

In manchen Behältern, die bereits anhand archäologischer Indizien mit Wein in Verbindung gebracht wurden, ließen sich Rückstände von Tartrat finden. In den so genannten Bier- und Lochbodengefäßen wurden Rückstände von Oxalat ermittelt (allerdings schienen die Lochbodengefäße auf mindestens zweifache Weise verwendet worden zu sein). Da in den Biergefäßen kein Tartrat gefunden wurde, scheidet Wein oder besser Traubensaft als Startermedium (Hefezellen an der Traubenoberfläche) für die Fermentation aus. Hingegen ließen die Reste von Oxalat an den Innenwandungen der großen Gefäße und der Lochbodengefäße die Vermutung aufkommen, dass sie mit der Verarbeitung von Getreide in wässrigem Milieu in Zusammenhang standen. Tabelle 1 zeigt auf, wie häufig besonders in den so genannten Biergefäßen und Lochbodengefäßen Oxalatspuren gefunden wurden. Bei der Malz- $^{14}$ und Bierbereitung entstehen Oxalatkristalle grundsätzlich, wenn Getreide mit Wasser im Überschuss vermischt wird (siehe Tab. 2).

\begin{tabular}{lcccc} 
Oxalat [mg/l] & Gerste & Einkorn & Emmer & Weizen \\
\hline 100 g Getreide in 0,5 1 Wasser & 5,1 & 6,0 & 3,5 & 5,7 \\
200 g Getreide in 0,5 1 Wasser & 7,6 & 10,0 & 6,3 & 9,7
\end{tabular}

Tab. 2: Oxalatausfällung verschiedener Getreide nach einem 24stündigen Weichvorgang (Oxalat in Wasser war nicht messbar).

Gleichwohl ist durch den Nachweis von Oxalat nicht zwangsläufig der Beweis für Bier erbracht, da es auch andere Ursachen für eine Oxalatausfällung geben kann. So könnte ein Oxalateintrag auch von anderen Pflanzen wie dem Rhabarber herrühren (290-640 mg Oxalsäure/l). ${ }^{15}$

13 Fritz Feigel, Tüpfelanalyse, Bd. 2, Organischer Teil, Frankfurt a.M. 1960, S. 356-362.

14 Malz: künstlich zum Keimen gebrachtes Getreide. Vorläufiges Biergesetz, §8, Abs. 3, Fassung vom 29. Juli 1993. Zweck des Mälzens ist die Enzymerzeugung und die Transformation wasserunlöslicher, hochmolekularer Substanzen in wasserlösliche, niedermolekulare Stoffe, wie z.B. Aminosäuren, vergärbare Zucker und essentielle Metaboliten für die Hefeernährung. Fritz Hayduck, Illustriertes Brauerei-Lexikon, Bd. 2, Berlin 1925, S. 129; Ian S. Hornsey, Brewing, Cambridge 1999, S. 15f.

15 Siegfied Walter Souci, Walter Fachmann u. Heinrich Kraut, Food Composition and Nutrition Tables, Stuttgart 2000, S. 728. 
Vereinzelt wurden auch (fossile?) Hefezellen mikroskopiert. Hefen sind aber ubiquitär in der Umgebung enthalten und sind somit ebenfalls, wenn fossil, nur ein Indiz, aber kein zwangsläufiger Beweis für eine bewusste Fermentation.

Schließlich ließen sich Stärkekörner auf wenigen Scherben nachweisen, häufiger jedoch an einem untersuchten Läufer einer Sattelmühle. Solche Sattelmühlen (in bemerkenswerter Fundsituation siehe Abb. 4) dienten dem häuslichen Getreidemahlen in den einzelnen Haushalten und wurden praktisch im gesamten Stadtbereich gefunden.

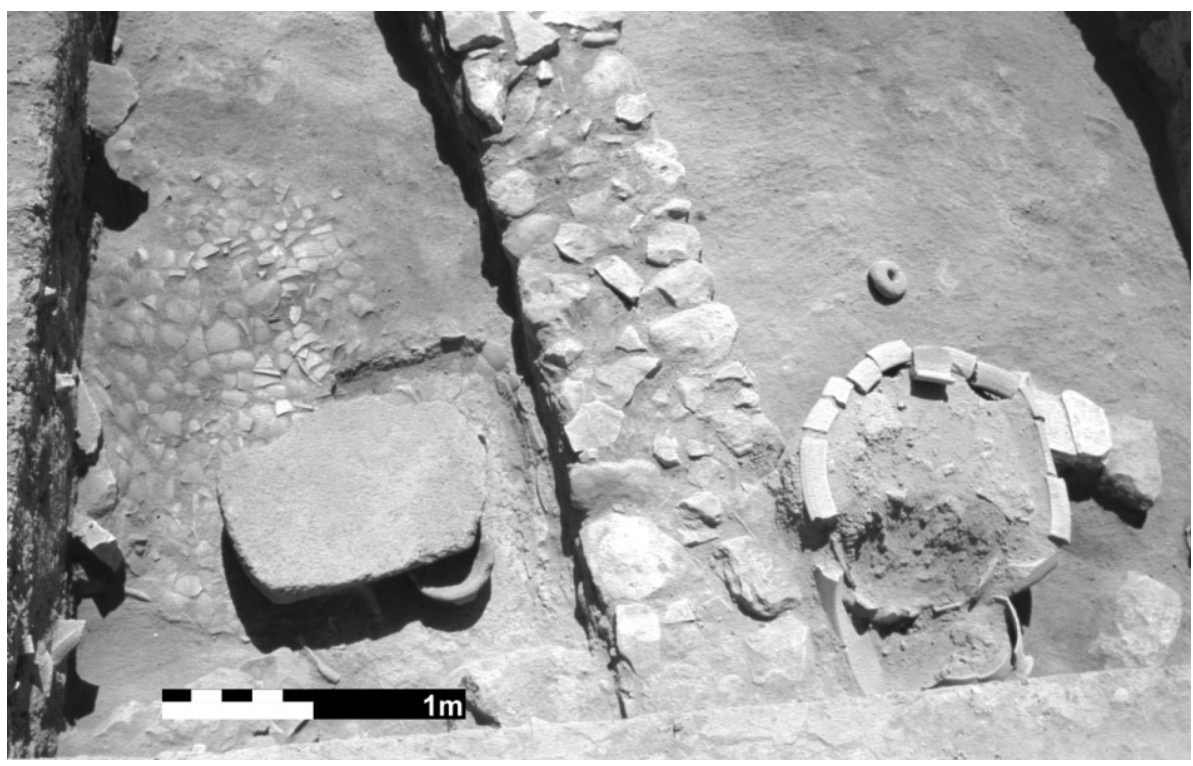

Abb. 4: Eine Sattelmühle (links) und ein Biergefäß (rechts) in zwei benachbarten Nebenräumen von Haus 17 der Weststadt von Tall Bazi. Bemerkenswert ist die aus zwei Hälften einer Steinschale fabrizierte Mehlauffangvorrichtung an den Ecken der Sattelmühle.

Wichtige Arbeitsutensilien des Brauprozesses wie Rührlöffel, Filtrationsmaterial (wenn überhaupt filtriert wurde, dann eventuell mit Stroh oder Textilien) und Schilfmatten als Arbeitsunterlagen haben sich zwar nicht erhalten, dürfen aber aufgrund keilschriftlicher Belege angenommen werden.

Als erstes Ergebnis des interdisziplinären Projektes ließ sich also feststellen, dass die großen Gefäße möglicherweise im Bierbereitungsprozess eine Rolle spielten. Die Tatsache, dass das Biergefäß unbeweglich geworden ist (siehe Abb. 3), setzte voraus, dass der darin stattfindende Prozessschritt unter hygienischen Gründen weniger kritisch beurteilt wurde; denn der tonnenförmige Behälter konnte zur Reinigung nicht umgedreht werden. Durch den Bodenkontakt war zusätzlich ein kühlender Effekt gegeben, der besonders 
in den Sommermonaten zu berücksichtigen war. Da das Gefäß nur zur Hälfte in den Boden eingelassen und der Rest von der Umgebungstemperatur beeinflusst war, ergab sich ein Temperaturgradient ${ }^{16}$. Er entsteht besonders während des Gärvorganges (lediglich 2,7\% der möglichen Energie wird in der anaeroben Phase chemisch gebunden, der Rest ist Wärmeenergie ${ }^{17}$ ) und fördert die Zirkulation innerhalb des Gefäßes.

Diese Überlegungen waren der Ausgangspunkt der experimentellen Phase dieses interdisziplinären Projektes. Vor Ort sollte unter Berücksichtigung der antiken klimatischen, botanischen und technologischen Gegebenheiten versucht werden, ein „Bazi-Bier“ nachzubrauen, um die aufgestellte Hypothese zu überprüfen.

\section{Technologische Situation}

Die Erwähnung von Bier in Keilschrifttexten belegt die weite Verbreitung des Brauens. Zuvorderst wird postuliert, dass die Bierbrauer bzw. -brauerinnen von Tall Bazi auf einen jahrhundertealten technologischen Erfahrungsschatz zurückgreifen konnten. Sie waren in der Lage, Bier in seinen verschiedenen, in Keilschrifttexten belegten Varianten ${ }^{18}$ reproduzierbar von guter Qualität herzustellen.

Keine befriedigende Auskunft liefern Keilschriftquellen zur Frage, wie welches Getreide in welchem Zustand zur Malz- und Bierbereitung verwendet wurde. Daher muss von technologischer Seite die Hypothese aufgestellt werden, dass Malz - wie auch heute noch - ein fester Bestandteil der Bierherstellung war. Ansonsten ist die ernährungsphysiologische und alkoholische Ausbeute viel zu gering, da die notwendigen amylolytischen Enzyme ${ }^{19}$ fehlen, die die native Getreidestärke in hefeverwertbare Zucker umwandeln können. Diese Zucker wiederum werden von der Hefe in Alkohol umgesetzt. Tabelle 3 zeigt die Alkoholausbeute mit verschieden vorbehandeltem Getreide, wobei mit Malz deutlich die höchste Ausbeute erreicht wird.

Diese amylolytischen Enzyme sind folglich nur dann in ausreichendem Maße verfügbar, wenn das Getreide gekeimt ist und somit der Definition für Malz entspricht. Daraus erschließen sich experimentell zwei denkbare Varianten von gekeimtem Getreide: Zum einen das nicht durch Hitzeeinwirkung wachstumsbegrenzte Grünmalz und zum anderen das durch einen Darrvorgang klar fixierte Darrmalz:

16 Temperaturgradient: räumlicher Temperaturunterschied zwischen dem ungekühlten oberen Teil und dem gekühlten, weil eingegrabenen, unteren Teil der Keramik, der zu einer Konvektion der Würze führt.

17 Ludwig Narziss, Abriss der Bierbrauerei, Weinheim 2001, S. 199.

18 Röllig (wie Anm. 8), S. 19-78.

19 amylolytische Enzyme: Bezeichnung für reaktionskatalysierende Verbindungen, die Stärke in kurz- und mittelkettige Saccharide überführen. Fritz Hayduck, Illustriertes Brauerei-Lexikon, Bd. 1, Berlin 1925, S. 234 u. 278. 


\begin{tabular}{|c|c|c|c|c|c|c|c|c|}
\hline \multirow[b]{2}{*}{ Zustand } & \multicolumn{5}{|c|}{ Gerste } & \multicolumn{2}{|c|}{$\begin{array}{l}\text { vorverkleisterte } \\
\text { Gerste }\end{array}$} & \multirow{2}{*}{$\begin{array}{c}\text { Malz } \\
\text { Schrot }\end{array}$} \\
\hline & Korn & Schrot & Korn & Schrot & $\begin{array}{c}\text { Korn } \\
\text { (gekocht) }\end{array}$ & Korn & Schrot & \\
\hline Behandlung & \multicolumn{2}{|c|}{ ungekocht } & \multicolumn{2}{|c|}{ gekocht } & gequetscht & - & - & - \\
\hline $\begin{array}{l}\text { Alkohol [Vol \%] } \\
\text { scheinbarer }\end{array}$ & 0,10 & 0,86 & 0,03 & 3,05 & 0,02 & 0,49 & 0,55 & 5,99 \\
\hline $\begin{array}{l}\text { Extrakt }^{20}[\text { GG \%] } \\
\text { Stammwürze }\end{array}$ & 0,25 & 1,38 & 0,48 & 1,90 & 0,69 & 1,77 & 0,11 & n. b. \\
\hline [GG \%] & 0,46 & 3,08 & 0,55 & 7,78 & 0,71 & 2,73 & 2,13 & 11,28 \\
\hline
\end{tabular}

Tab. 3: Alkoholausbeute nach einer Endvergärung (Analytik nach MEBAK ${ }^{21}$ ) mit verschieden vorbehandeltem Getreide (n. b. = nicht berechenbar).

- Das Grünmalz ${ }^{22}$ ist nicht lagerfähig und somit nur unmittelbar nach der Herstellung verwendbar. Dies bedeutet organisatorische Probleme, da die Malzbereitung deutlich mehr Zeit in Anspruch nimmt als die Maische- und Bierbereitung. Das Zerkleinern kann nicht mit Sattelmühlen erfolgen, da die Körner verschmieren und dadurch der Schwund sehr hoch ist. In Mörsern lässt sich Grünmalz nur bedingt und mit einer ebenfalls schlechten Ausbeute zerquetschen und verreiben. Zusätzlich wurden nur in etwa 20\% der Weststadthäuser entsprechend große Mörser gefunden. Ein weiterer Nachteil besteht darin, dass der entstandene Keimling schlecht trennbar ist und somit ein unangenehmer bitterer Geschmack in das Endprodukt eingetragen wird. Ein Vorteil ist jedoch, dass dieses Grünmalz sehr enzymstark ist.

- Das Darrmalz ${ }^{23}$ ist lagerfähig und besitzt ausreichend malzeigene Enzyme, da mit Temperaturen von $60{ }^{\circ} \mathrm{C}$, die vor Ort in der Sonne problemlos

20 scheinbarer Extrakt: E. bezeichnet die Summe aller Stoffe, die durch das Maischen in Lösung gebracht werden. Der scheinbare Extrakt wird durch die Ermittlung der Dichte bestimmt. Im Bier wird der scheinbare Extrakt gemessen, da der enthaltene Alkohol das spezifische Gewicht des Bieres vermindert. Werner Back, Ausgewählte Kapitel der Brauereitechnologie, Nürnberg 2005, S. 13; Hayduck (wie Anm. 19), S. 90f. u. 286.

21 Endvergärungsgrad: bezeichnet den prozentualen Anteil des vergärbaren Extraktes am Gesamtextrakt unter Laborbedingungen. Hayduck (wie Anm. 19), S. 273; Heinrich Pfenninger, Methodensammlung der Mitteleuropäischen Brautechnischen Analysenkommission (MEBAK) - Brautechnische Analysenmethoden, Bd. 2, Freising-Weihenstephan 2002, S. 66-69.

22 Grünmalz: bezeichnet zum Keimen gebrachte, nicht lagerfähige Gerste in einem bestimmten Wachstumsstadium, die (noch) nicht getrocknet wurde. Hayduck (wie Anm. 19), S. 465; Hans-Dieter Belitz u. Werner Grosch, Lehrbuch der Lebensmittelchemie, Berlin, Heidelberg u. New York 1992, S. 811.

23 Darrmalz: bezeichnet Malz, das durch Trocknung (Darren) lagerfähig gemacht wird. Durch die Hitzeeinwirkung erfolgt ebenfalls die Bildung von Farb- und Aromastoffen. Hayduck (wie Anm. 19), S. 219f.; Belitz/Grosch (wie Anm. 22), S. 811. 
erreicht werden, eine extrem schonende Trocknung möglich ist. Durch die Wärme entstehen Aroma- und Farbstoffe, die in das Endprodukt eingetragen werden. Mit den häufig vorgefundenen Sattelmühlen kann Malz schnell, wirkungsvoll und unter Erzielung einer für die Bierbereitung optimalen Partikelverteilung geschrotet werden.

Trotz der unübersehbaren Vorteile von Darrmalz (vereinfacht nur noch Malz genannt) bedeutet dies keineswegs die ausnahmslose Verwendung von Malz. Damals wie auch heute ist ein gangbarer Mittelweg gesucht worden, der Zeit- und Arbeitsaufwand gegen den Nutzen aufwiegt. Somit wurden sicherlich auch unvermälzte Stärkelieferanten verwendet. ${ }^{24}$ Denkbar wären Formen vorverkleisterter Stärke ${ }^{25}$, wie sie in Bulgur oder Brot vorkommen:

- Bulgur ist lagerfähig und sein Vorkommen aufgrund verschiedener Hinweise aus der Fundsituation, wie der Oxalatbefunde in den Kochtöpfen, wahrscheinlich. Das Zerkleinern gelingt mit Sattelmühlen problemlos, mit dem Mörser jedoch nur schlecht.

- Das Gerstenbrot (Fladenbrot) ist aufgrund der leichten Feuchte im Innern schimmelanfällig und daher nur bedingt lagerfähig. Das vor Ort nachgebackene syrische Gerstenbrot erforderte wegen fehlender Klebereigenschaften einen gewissen Weizenmehlanteil ${ }^{26}$. Von Nachteil erweist sich weiter die schlechte Handhabung solcher Fladenbrote. Eine denkbare Verwendung von Gerstenbrot in der Bierbereitung Tall Bazis wäre sein unmittelbarer Einsatz beim Maischen ${ }^{27}$. Jedoch wäre solch ein Brot ohne Enzymkraft. Ein enzymstärkerer Brottyp kann aus Malz hergestellt werden. Dessen Brotteig ist jedoch zu flüssig, als dass er ohne Backformen, die nicht in Tall Bazi gefunden wurden, herstellbar gewesen wäre. Zusätzlich sprechen die größtenteils gefundenen Ofentypen, Tannure ${ }^{28}$, ebenfalls gegen ein Malzbrot. Somit scheidet Brot als Extrakt- und Enzymlieferant im Fall Tall Bazi für die damalige Bierbereitung aus.

Um während der Maischarbeit aus Stärke vergärbaren Zucker mittels malzeigener Enzyme zu bilden, spricht ein weiterer Aspekt für die Verwendung

24 Vgl. hierzu auch die Diskussion bei Justin Jennings, Kathleen L. Antrobus, Sam J. Atencio, Erin Glavich, Rebecca Johnson, German Loffler u. Christine Luu, Drinking Beer in a Blissfull Mood, in: Current Anthropology 46, 2005, S. 279-281.

25 vorverkleisterte Stärke: Native, unverkleisterte Stärke kann durch malzeigene Enzyme nicht in vergärbare Zucker gespalten werden. Erst nach Erreichen der Verkleisterungstemperatur können sie die Stärke abbauen. Hayduck (wie Anm. 14), S. 109.

26 Im 13. Jahrhundert v. Chr. könnte als Weizenersatz auch der am Fundort als antike Getreideart nachgewiesene Emmer gedient haben.

27 Maischen: bezeichnet das Mischen von Wasser und geschroteter Gerste. Ziel ist die Überführung der wasserlöslichen und der wasserunlöslichen Substanzen in wässrige Lösung. Hayduck (wie Anm. 14), S. 106.

28 Tannure: Arabische Bezeichnung für einen etwa hüfthohen zylinderförmigen Ofen, dessen innere erhitzte senkrechte Wand als Kontaktfläche beim Backen der Brote dient. 
von Malz. Dies ist die Aminosäureausstattung der Malzwürze ${ }^{29}$, die eine problemlose Wiederverwendung der Hefe ermöglicht. Ist dies nicht der Fall, wie bei Verwendung von Rohfrucht ${ }^{30}$, so nehmen die Hefevermehrung und die Alkoholausbeute ab (siehe Tab. 4).

\begin{tabular}{l|cc} 
& Alkohol [Vol \%] & Mio. Hefezellen/ml \\
\hline 0. Führung ${ }^{31}$ & 0,55 & 15 \\
1. Führung & 0,27 & 12 \\
2. Führung & 0,21 & 7
\end{tabular}

Tab. 4: Alkoholausbeute und Hefezellzahl von Gerstenrohfruchtwürze nach wiederholter Hefeführung.

Eine Alternative zur wiederholten Hefeführung ist die spontane Gärung. Dies ist sicherlich eine sehr ursprüngliche Fermentationstechnologie für Bier gewesen. Die Gärung kann aber sehr viel Zeit erfordern (bis zu 2 Jahren) ${ }^{32}$ und führt nicht immer zu einem reproduzierbaren Ergebnis. Es wäre verwunderlich, hätte ein/e Bierbrauer/in nicht den Nutzen einer beeindruckend ,lebenden“", gärenden Schaumdecke der obergärigen Fermentation ${ }^{33}$ erkannt. Abbildung 5 zeigt solch eine Schaumdecke während der Experimente in Tall Bazi.

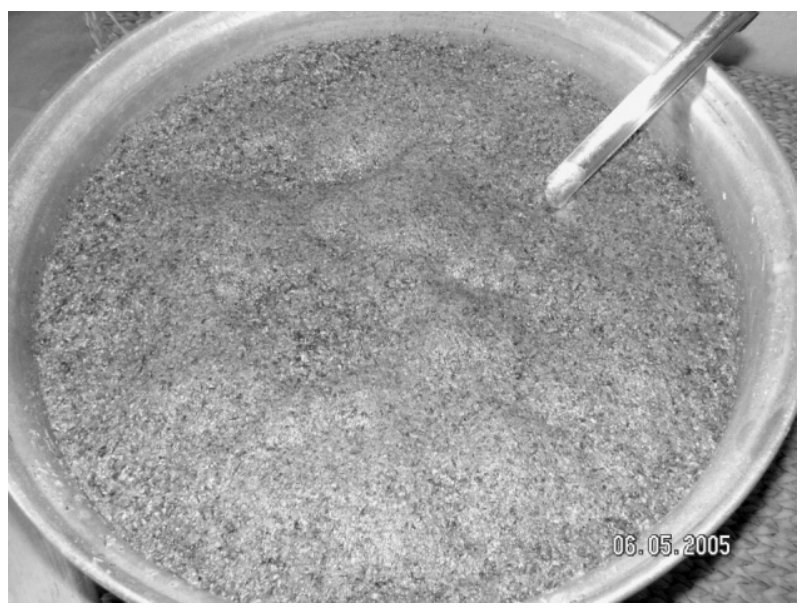

Abb. 5: Hefe- und Schaumdecke der mit obergäriger Hefe nach dem Kaltmaischverfahren hergestellten vergorenen Würze.

29 Würze: wässrige Lösung aller bei Maischen in Lösung gegangenen Substanzen. Hayduck (wie Anm. 14), S. 417.

30 Rohfrucht: unvermälztes Getreide. Hayduck (wie Anm. 14), S. 251.

31 Führung: bezeichnet die Anzahl der Chargen, die durch dieselbe Hefe vergoren wurden.

32 Roger A. Mussche, Spontaneous Fermentation. The Production of Belgian Lambic, Gauze and Fruit Beers, in: Brewers' Guardian 128, 1999, Nr. 1, S. 19-24.

33 obergärige Fermentation: In der Brauerei werden zwei verschiedene Arten der alkoholischen Gärung unterschieden. Die Obergärung ist gekennzeichnet durch das Aufsteigen der obergärigen Hefe während der Gärung. Hayduck (wie Anm. 14), S. 197; bei der Untergärung sinkt die Hefe zu Boden, ebd. S. 344f. 
Es ist daher nahe liegend, dass bereits in der Spätbronzezeit, wenn nicht gar früher eine, wenn auch primitive Art der „Hefewirtschaft“ existierte, nämlich dergestalt, dass aus der vital erscheinenden Schaumdecke des vorhergehenden Gäransatzes Hefe entnommen wurde, um die nächste Maische wiederum in eine rasche Gärung zu versetzen.

Es wurde während der Ausgrabung erwartungsgemäß kein Beweis für die Verwendung von Hopfen gefunden. Andere Gewürze wie Thymian oder minzartige Kräuter, die auch heute noch in dieser Region angetroffen werden, konnten in keinen klaren Kontext zur Bierbereitung gebracht werden.

\section{Altorientalische Mälzungs- und Brautechnologie, experimentell erschlossen}

Alle dargestellten Fund-, Klima- und botanischen Gegebenheiten in Kombination mit den theoretischen Erwägungen lassen klar auf den Kern der Technologie, auf ein Kaltmaischverfahren, schließen. Darauf aufbauend, dass gekeimte Gerste in den beschriebenen Gefäßen verarbeitet wurde, sprach ein Aspekt besonders für das nachfolgend beschriebene experimentelle Maischverfahren. Es war wenig Heizmaterial vorhanden, um eine gezielte Temperaturerhöhung der Maische zu bewirken. Hierzu müsste die Maische selbst erhitzt oder wenigstens Maischereste gekocht werden. Dies lässt aber die Größe der Kochgefäße (15 l) im Vergleich zu den großen Maisch-/Gärgefäßen (200 1) keineswegs zu. Als länger brennendes Material kommt nur Holz, Tierkot und eventuell Maischetreber ${ }^{34}$ in Frage. Der heute noch häufig vorkommende und verwendete Reisig erzeugt nur eine kurzzeitig hohe Wärmeentwicklung. Der für die Kochprozesse ungenügende Vorrat an Brennmaterial sowie die vorgefundenen Gefäßgrößen machten es unmöglich, dass Kochmaischen mittels direkter Befeuerung oder erhitzter Steine zum Erhitzen der Gesamtmaische herangezogen wurden. Die Experimente waren so ausgelegt, dass die Herstellung eines trinkfähigen Bieres ohne künstliche Wärmeeinwirkung geprüft wurde. Von diesem extremen Verfahren unterschied sich die frühere Bereitung sicherlich, da es zwar wenig, aber doch Heizmaterial gab.

Der Einsatz eines Kaltmaischverfahrens bedeutet, dass ein Enzympotential vorhanden sein muss und die Stärke eine gewisse Vorverkleisterung benötigt. Beides stellt das Malz zur Verfügung. Wie die Mälzung der einheimischen Gerste vonstatten ging, wird nachfolgend beschrieben.

34 Maischetreber: In Wasser unlösliche Bestandteile des Malzes. Hayduck (wie Anm. 19), S. 135; Dennis E. Briggs, Malts and Malting, London 1998, S. 242ff. Eiweißhaltiges Abfallprodukt bei der Bierherstellung, gut geeignet als Viehfutter. Hayduck (wie Anm. 19), S. 354f. 


\section{Mälzung}

Nach mehreren Versuchen stellte sich heraus, dass sich die Lochbodengefäße als Weich- und Keimgefäße hervorragend eigneten. In Abbildung 6 ist ein modernes, der antiken Keramik weitgehend entsprechendes Lochbodengefäß zum Zeitpunkt des Ausweichens ${ }^{35}$ abgebildet.

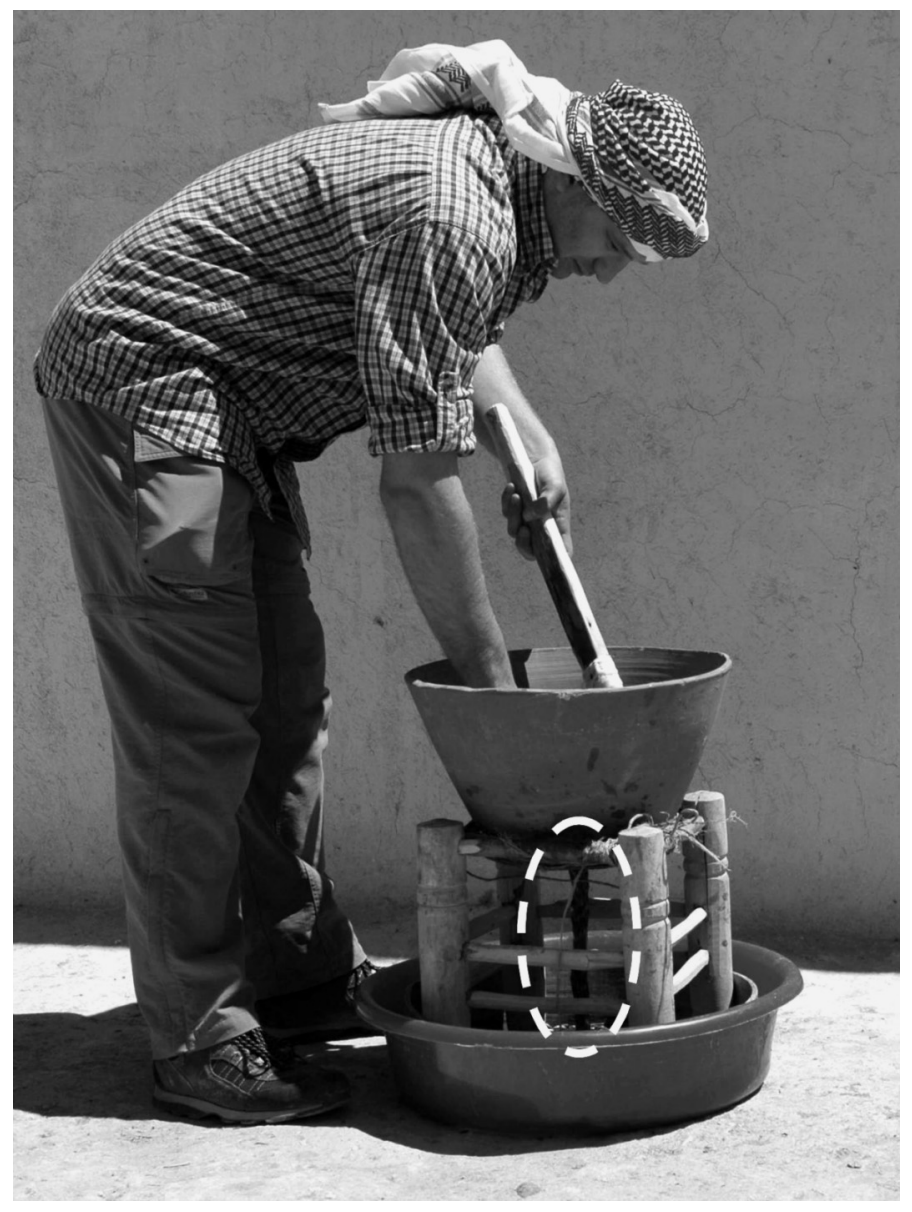

Abb. 6: Nasses Ausweichen der geweichten Gerste aus einem Lochbodengefäß.

Der starke Strahl in der unteren Mitte zeigt, dass das nasse Weichgut problemlos durch das Loch ausfließen kann, was eine immense Arbeitserleichterung darstellt. Die Keimung wurde einerseits in den Gefäßen, andererseits auf Matten (siehe Abb. 7), die es zu der damaligen Zeit ausreichend als Arbeitsfläche gab, ausgeführt. In beiden Fällen wurden als Arbeitsraum die Lehmziegelhütten genutzt, die sich in den Jahrtausenden wenig

35 Ausweichen: Überführung der Gerste aus der Weiche in die Keimvorrichtung. Hayduck (wie Anm. 19), S. 69; Narziss (wie Anm. 17), S. $23 f$. 
verändert haben. Der Vorteil dieser Materialien und Bauweisen ist, dass Tag und Nacht eine gleich bleibende Temperatur herrscht. Somit war die Temperatur während der Keimung auf etwa $24{ }^{\circ} \mathrm{C}$, zusätzlich bedingt durch die Verdunstungskälte, konstant. Zweimal am Tag wurde gewendet, bis nach vier Tagen Vegetationszeit die gewünschte Wurzelkeimlänge erreicht war.

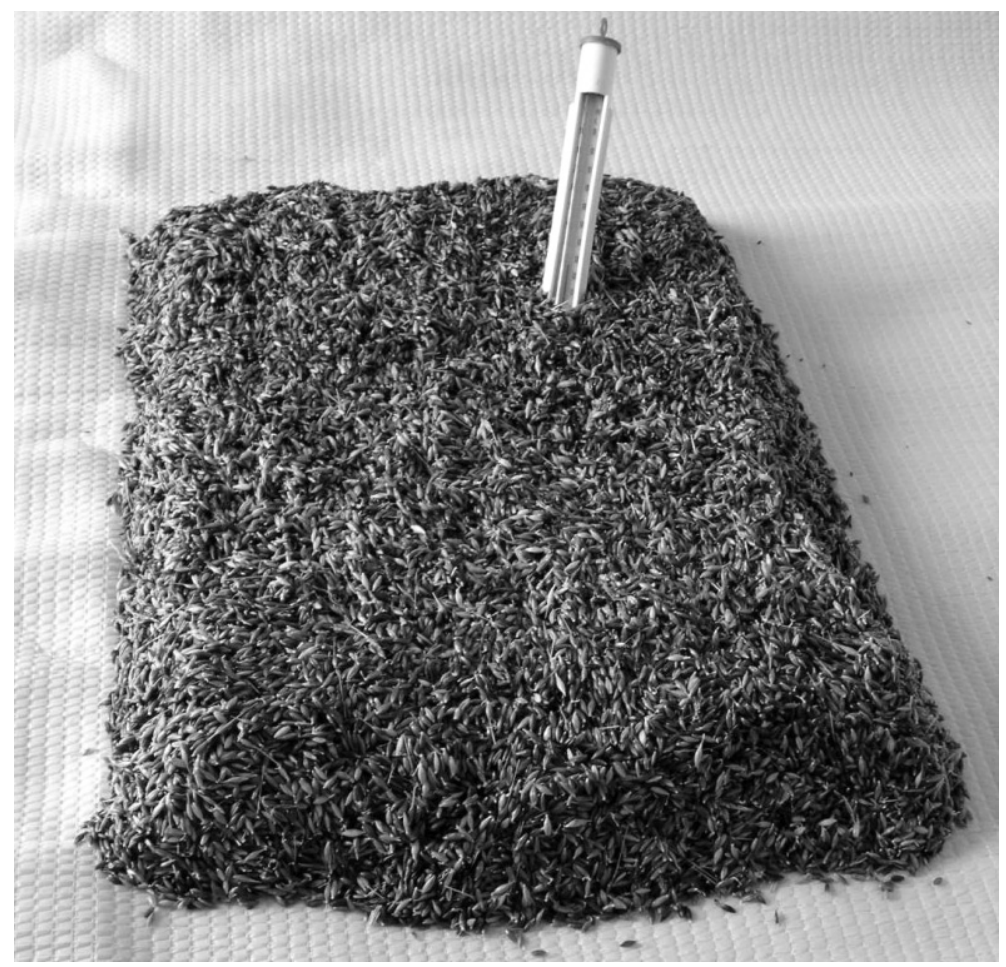

Abb. 7: Schwarze Gerste syrischer Provenienz im Stadium des Greifhaufens ${ }^{36}$ auf einer Schilfmatte in der Tennenmälzerei ${ }^{37}$.

Das Dach eines Lehmziegelhauses diente auch als Darre (siehe Abb. 8). Dabei wurden gewichtige saisonale Unterschiede registriert: In der heißen Spätsommerzeit war es problemlos möglich, $60^{\circ} \mathrm{C}$ zu erreichen, hingegen stieg im Frühling die Temperatur lediglich auf $45^{\circ} \mathrm{C}$. Dadurch wird eine saisonale Malzbereitung wahrscheinlich, da diese alten, noch heute verwendeten Gers-

36 Haufen: Fachbegriff aus der Mälzersprache, die eine Malzcharge zu einem bestimmten Prozesszeitpunkt beschreibt, wie z.B. zum Zeitpunkt des Greifens, wenn die Wurzeln der Körner ineinander greifen.

37 Tennenmälzerei: Mälzungssystem, bei dem die keimende Gerste auf einem befestigten Boden (Beton, Holz, Lehm) ausgebreitet wird. Hayduck (wie Anm. 14), S. 144f.; Briggs (wie Anm. 34), S. 341-352; Ludwig Narziss, Die Bierbrauerei in drei Bänden, Bd. 1: Die Technologie der Malzbereitung, Stuttgart 1999, S. 225-228. 


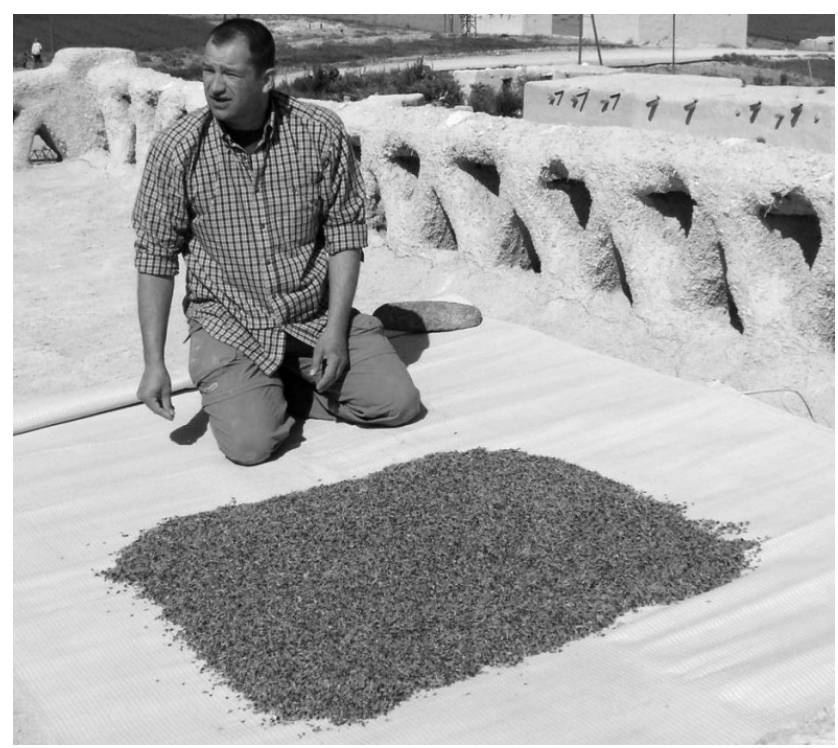

Abb. 8: Zum Trocknen und Darren auf einer Schilfmatte ausgebreiteter Haufen auf einem Lehmhüttendach.

tensorten eine lange Keimruhe ${ }^{38}$ aufweisen (Keimenergie ${ }^{39}$ 09/2004: $50 \%$ und 04/2005: $82 \%$ ). Dies zeigen die Malzdaten der Tabelle 5 deutlich. Nach beinahe einjähriger Ablagerung war es möglich, die Gerste zu einem besseren Malz zu verarbeiten.

Die Ergebnisse der Malzmerkmale sind in der Tabelle 5 im Vergleich zu einer am Lehrstuhl für Technologie der Brauerei I nach MEBAK-Standardverfahren ${ }^{40}$ vermälzten Gerste dargestellt.

Im nächsten Schritt mussten die trockenen Gerstenkörner (Rohfrucht, Bulgur $^{41}$, Malz usw.) zerkleinert werden. Dies geschah am effektivsten mit Sattelmühlen. Zwar werden für die Herstellung von ,opaque beers“442 in Afrika hauptsächlich Mörser verwendet, wie sie auch in Bazi gefunden wurden, aber nach eingehendem Vergleich beider Schrotungsmethoden stellte

38 Keimruhe: frisch geerntete Gerste befindet sich in einem Stadium der Keimruhe. Während dieser Zeit kann die Gerste nicht verarbeitet werden, da dies einen Selbstschutz der Pflanze gegen ein Auskeimen der Körner aufgrund ungünstiger Witterungsbedingungen am Halm bedeutet. Hayduck (wie Anm. 19), S. 401ff.; Narziss (wie Anm. 17), S. $12 \mathrm{f}$.

39 Keimenergie: prozentualer Anteil der Körner, die innerhalb von fünf Tagen zu Keimen beginnen. Hayduck (wie Anm. 19), S. 401ff.; Narziss (wie Anm. 17), S. 8.

40 MEBAK-Standardverfahren (Standardmälzung): Standardisierte Mälzung zum Vergleich unterschiedlicher Malze. Heinrich Pfenninger, Methodensammlung der Mitteleuropäischen Brautechnischen Analysenkommission (MEBAK) - Brautechnische Analysenmethoden, Bd. 1, Freising-Weihenstephan 1997, S. 179.

41 Bulgur: gekochte, ungeschrotete stärkehaltige Getreidekörner

42 opaque beer: ,opaque beers“ sind trübe Biere, hergestellt in Afrika. Grundlage für diese Biere sind meist vermälzter Sorghum oder kleinkörnige Hirse. Briggs (wie Anm. 34), S. 13-16. 


\begin{tabular}{|c|c|c|c|c|}
\hline Analyse & Einheit & $\begin{array}{l}\text { Bazi-Malz } \\
\text { (Standard) }\end{array}$ & $\begin{array}{l}\text { Bazi-Malz } \\
(9 / 04)\end{array}$ & $\begin{array}{l}\text { Bazi-Malz } \\
(4 / 05)\end{array}$ \\
\hline Extrakt & $\%$, wfr. & 72,2 & 71,2 & 69,5 \\
\hline Viskosität $\left(65^{\circ} \mathrm{C}\right)$ & $\mathrm{mPa} \times \mathrm{s}, 8,6 \%$ & 9,98 & 5,22 & 5,61 \\
\hline Verzuckerung & & $<15$ & keine & $15-20$ \\
\hline Endvergärungsgrad & $\%$ & 74,2 & 62,8 & 70,8 \\
\hline Kochfarbe, fotometrisch ${ }^{43}$ & $\mathrm{EBC}^{44}$ & 6,3 & 5,9 & 3,4 \\
\hline Rohprotein & $\%$, wfr. & 11,1 & 11,1 & 12,0 \\
\hline löslicher Stickstoff ${ }^{45}$ & $\mathrm{mg} / 100 \mathrm{~g} \mathrm{MTrS}$ & 444 & 427 & 491 \\
\hline $\mathrm{ELG}^{46}$ & $\%$ & 25,2 & 23,9 & 25,6 \\
\hline $\mathrm{FAN}^{47}$ & $\mathrm{mg} / 100 \mathrm{~g} \mathrm{MTrS}$ & 79 & 59 & 88 \\
\hline$\beta$-Glucane ${ }^{48}\left(65^{\circ} \mathrm{C}\right)$ & $\mathrm{mg} / \mathrm{l}$ & 1634 & 987 & 1088 \\
\hline$\alpha$-Amylase ${ }^{49}$ & ASBC, wfr. & 9 & 6 & 20 \\
\hline DMS-Vorläufer ${ }^{50}$ & ppm, lftr. & 3,6 & 3,2 & 8,3 \\
\hline
\end{tabular}

Tab. 5: Malzmerkmale der Gerste der Ernte 2004 im September 2004 und April 2005 in Tall Bazi vermälzt im Vergleich zu ihrer Standardmälzung.

sich die Sattelmühle als überlegen heraus. Die Abbildung 9 zeigt solch einen Schrotvorgang, wobei pro Stunde 1,4 kg geschrotet werden konnten.

\section{Maisch-, Würzebereitungs- und Gärungsprozess}

Die Gründe für ein Kaltmaischverfahren sind im Vorangegangenen ausführlich dargelegt worden. Mit einem Schrot/Wasser-Mischungsverhältnis von 1:8,3 wurde unter kräftigen Rührbewegungen bei $34{ }^{\circ} \mathrm{C}$ für 15 Minuten eingemaischt. Danach wurde die hergeführte Mischung aus Saccharomycesund Schizosaccharomyces-Hefen sowie Laktobazillen-Species der Maische zugegeben und für 36 Stunden bei etwa $24^{\circ} \mathrm{C}$ stehengelassen. Eine Mischung

43 Kochfarbe: Methode zur Vorhersage der zu erwartenden Bierfarbe. Back (wie Anm. 20), S. 15; Pfenninger (wie Anm. 40), S. $240 f$.

$44 E B C$ : European Brewery Convention

45 löslicher Stickstoff: Menge der unter Standardbedingungen in Lösung gegangenen Stickstoffverbindungen. Pfenninger (wie Anm. 40), S. 254.

46 ELG (Eiweißlösungsgrad): bezeichnet den prozentualen Anteil am Gesamteiweiß des Malzes, der unter Standardbedingungen in Lösung gegangen ist. Pfenninger (wie Anm. 40), S. 257.

47 FAN (Freier Amino-Stickstoff): Menge an niedermolekularen Stickstoffverbindungen (hauptsächlich Aminosäuren). Pfenninger (wie Anm. 21), S. 62-65.

$48 \beta$-Glucane: $\beta$-Glucane sind Gerüstsubstanzen im Gerstenkorn. Die Menge an $\beta$-Glucanen lässt Rückschlüsse auf den Fortschritt der Malzlösung zu. Pfenninger (wie Anm. 40), S. $274 f$.

$49 \alpha$-Amylase: Maß für die Enzymaktivität stärkeabbauender Enzyme. Pfenninger (wie Anm. 40), S. 264.

$50 D M S$-Vorläufer: beschreibt das Potential zur DMS-Bildung, das einen gemüseartigen Fehlgeschmack in Bier hervorrufen kann. Heinrich Pfenninger, Methodensammlung der Mitteleuropäischen Brautechnischen Analysenkommission (MEBAK) - Brautechnische Analysenmethoden, Bd. 3, Freising-Weihenstephan 1996, S. 31-41; Back (wie Anm. 20), S. 14. 


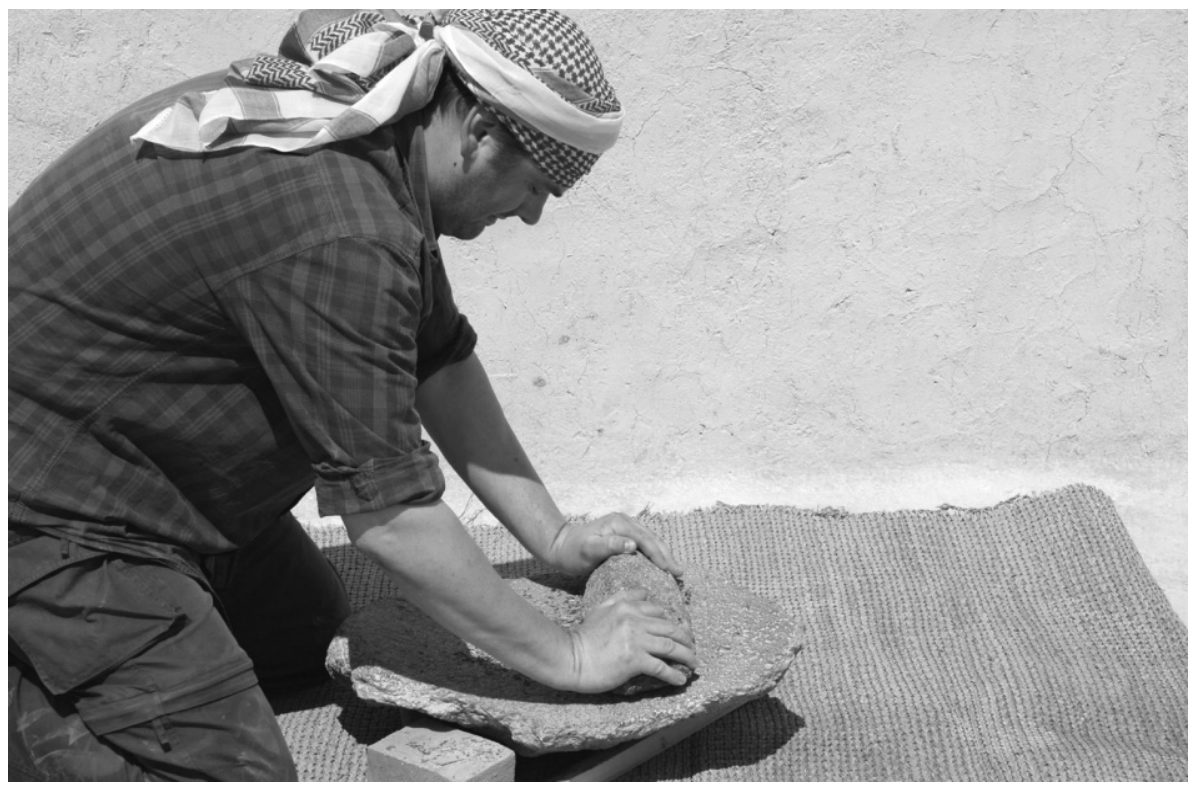

Abb. 9: Schrotung von Bazimalz mit einer originalen spätbronzezeitlichen Sattelmühle und Läufer.

aus alkoholischer und milchsaurer Vergärung ist die denkbar wahrscheinlichste, die nach anfänglich spontaner Vergärung auftritt. Dies wurde auch in Versuchen vor Ort nachvollzogen. Die resultierenden Biere wurden bewusst so dünn eingemaischt, um einerseits eine ausreichende Verzuckerung ${ }^{51} \mathrm{zu}$ erhalten und um andererseits wenig Alkohol (siehe Tab. 6) entstehen zu lassen; letzteres deswegen, weil - wie wiederum aus Keilschriftquellen bekannt ist - diese Getränke auch von Kindern getrunken wurden, um den Durst zu löschen und nicht, um sich zu berauschen.

\begin{tabular}{l|cc} 
& „Pombe“ $^{\text {“ }}$ & Hefengemisch \\
\hline Stammwürze $^{52}$ [GG \%] & 2,64 & 3,71 \\
Alkohol [Vol \%] & 0,88 & 1,60 \\
Endvergärungsgrad [\%] & 76,8 & 87,0 \\
pH & 3,65 & 3,90 \\
photometrische Jodprobe & & 0,118 \\
Thiobarbitursäurezahl $^{54}$ & 0,092 & 3
\end{tabular}

Tab. 6: Biermerkmale der Versuchsude mit unterschiedlichen Hefen und Milchsäurebakterien.

51 Verzuckerung: bezeichnet den Vorgang des Stärkeabbaus mittels amylolytischer Enzyme. Deren Wirkung ist größer, wenn ein höheres Schrot-Wasser-Verhältnis zum Einmaischen verwendet wird. Die Verzuckerung ist abgeschlossen, wenn die Jodnormalität erreicht ist. Hayduck (wie Anm. 14), S. 109. 
Die beiden verschiedenen Biere hatten den erwarteten niedrigen Alkoholgehalt. Sie waren hoch vergoren und mit einem $\mathrm{pH}$-Wert von $<4,0$ erfüllen sie eine gewisse Sicherheit gegen mikrobiellen Befall. Die Biere waren über zwei Monate stabil. Ein interessantes Detail ist, dass die Biere jodnormal waren, obwohl die Maischarbeit nur aus dem ausgiebigen Vermengen von Wasser mit Schrot bestand. Der letzte Schritt des Experiments war die mit Spannung erwartete Verkostung. Das sehr gemischt zusammengesetzte Verkosterpanel vor Ort (siehe Abb. 10) bescheinigte den Bieren einen angenehm spritzigen Charakter mit hohem Genusspotential.

Allerdings wurde Bier im Alten Orient bisweilen so genossen, dass es mittels langer Saugrohre aus einem gemeinsamen Gefäß gesogen wurde (antikes und aktuelles Beispiel in Abb. 11). Auf die Spitze der Saugrohre wurden bronzene Filterspitzen (siehe Abb. 12) gesteckt, die zugleich Rückschlüsse auf eine ungenügende Trennung der festen und flüssigen Bestandteile des Bieres zulassen.

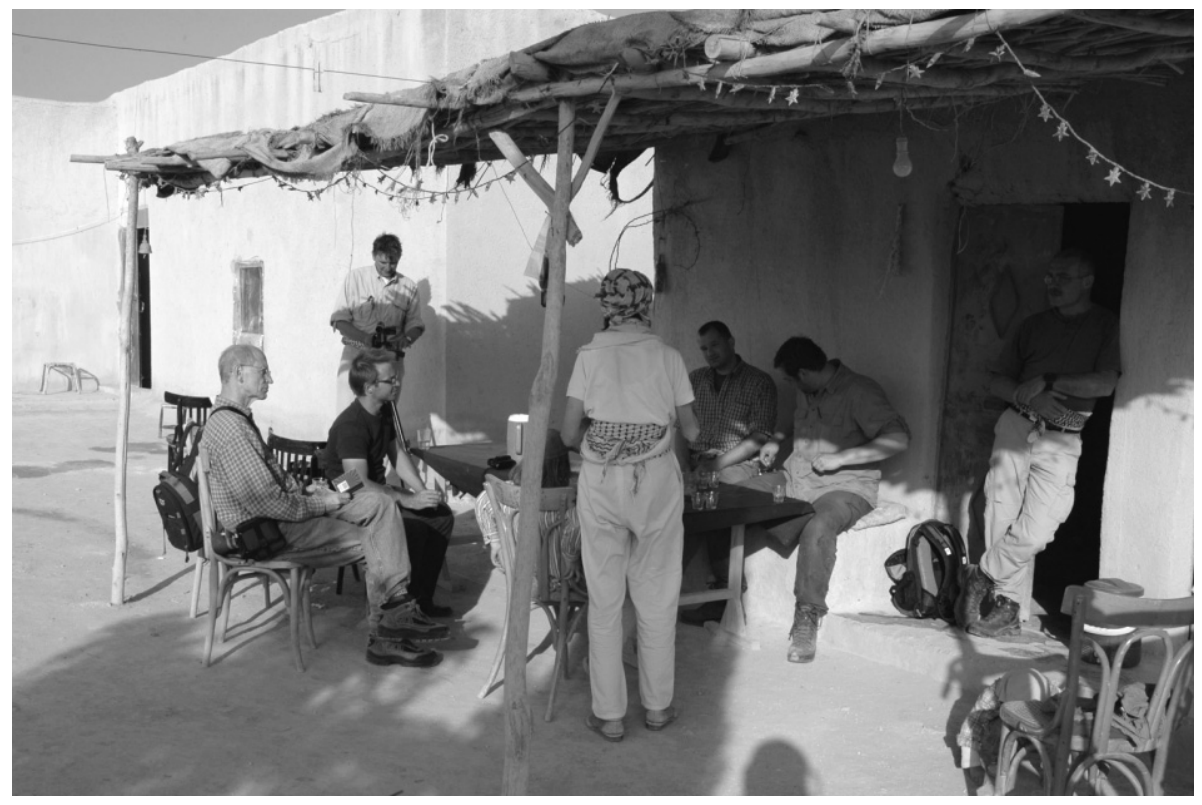

Abb. 10: Wieder einmal Bier in Bazi! Die Autoren mit Gästen bei der Bierprobe.

52 Stammwürze: bezeichnet die wässrige Extraktlösung, die zur Fermentation verwendet wird. Hayduck (wie Anm. 14), S. 298.

53 photometrische Jodprobe: Bestimmung der Jodnormalität. Mittels der Jodprobe wird der fortschreitende Stärkeabbau während des Maischens kontrolliert. Ist eine Würze jodnormal, ist die gesamte Stärke zu vergärbaren Zuckern abgebaut. Pfenninger (wie Anm. 40), S. 234; Hayduck (wie Anm. 14), S. 8.

54 Thiobarbitursäurezahl: Maß für die thermische Belastung. Pfenninger (wie Anm. 21), S. 35f. 


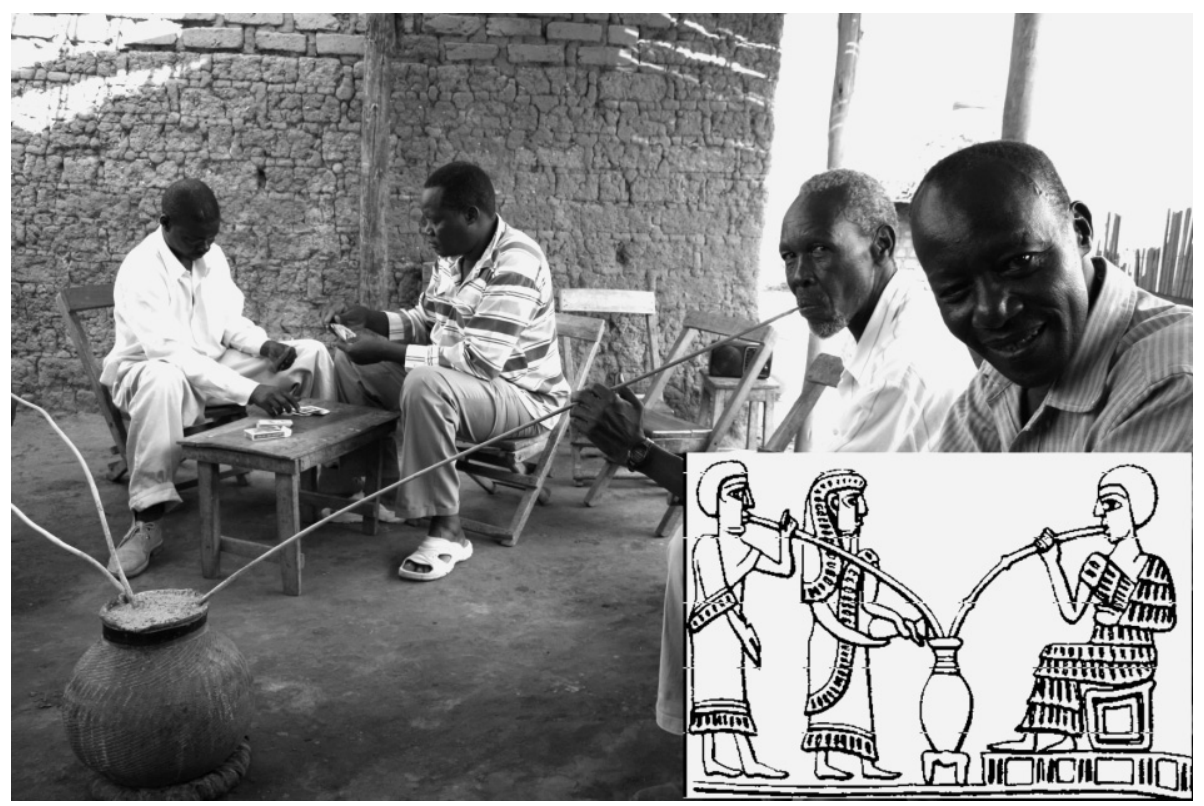

Abb. 11: Großes Bild: Männerrunde in Uganda beim Genuss eines „opaque beer“ mit Trinkhalm (Foto mit freundlicher Genehmigung von Michael Eberhard/Weihenstephan). Rechts: Mit Trinkrohr trinkende Personen (Berlin, Vorderasiatisches Museum, Inv.-Nr. VA 522; Zeichnung: D. Hinz).

Abb. 12: Eine Saugrohrspitze aus Bronze mit mehreren Öffnungen, um Feststoffpartikeln zurïckzuhalten; gefunden im Haus Nr. 25 der Weststadt von Tall Bazi.
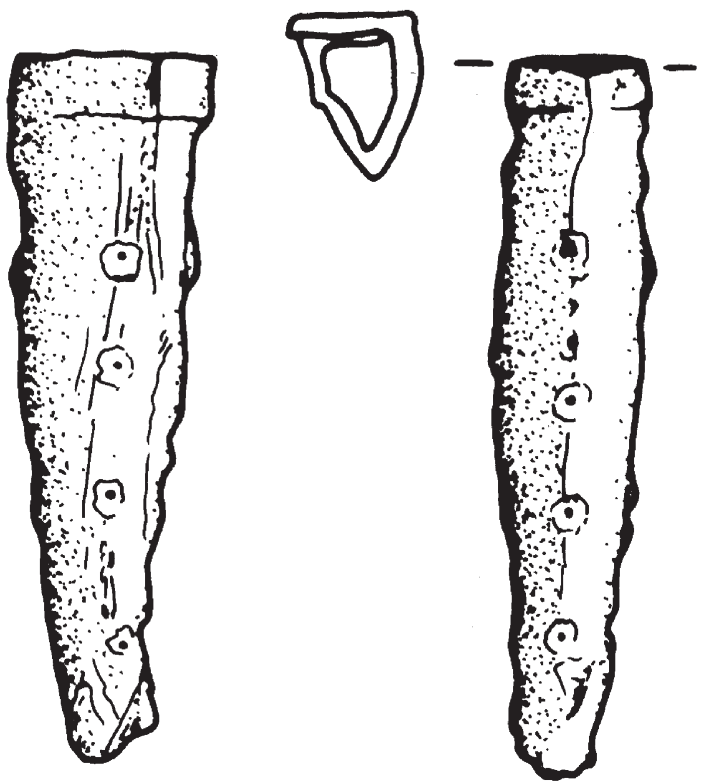


\section{Ergebnis und Ausblick}

Eine außergewöhnlich gute archäologische Befundsituation in der altorientalischen Wohnsiedlung von Tall Bazi in Nordsyrien erlaubte, Bierbrauen in seinem mesopotamischen Ursprungsgebiet theoretisch zu untersuchen und in Versuchsreihen praktisch nachzustellen. In interdisziplinärer Zusammenarbeit gelang es zunächst, durch Inhaltsuntersuchungen antiker Gefäßscherben festzustellen, dass mit an Sicherheit grenzender Wahrscheinlichkeit in nahezu allen der etwa 50 ausgegrabenen Wohnhäuser aus dem 13. Jahrhundert v. Chr. Bier gebraut wurde. In einem zweiten Schritt wurde versucht, unter Berücksichtigung brautechnologischer Prinzipien und auf der Basis keilschriftlicher Informationen das Verfahren der damaligen Malz- und Bierbereitung zu rekonstruieren. Wichtige Parameter waren hierbei natürliche sowie anthropogene Gegebenheiten (Klima, Energieressourcen usw. einerseits, die antike Ausstattung andererseits). Am wahrscheinlichsten ist ein Kaltmaischverfahren anzunehmen, das in den großen Biergefäßen ablief. Das benötigte Malz wurde produziert, indem es in den Lochbodengefäßen geweicht und gekeimt wurde; die Keimung des Grünmalzes wurde auf dem Sonnen beschienenen Dach, wo es auf Matten ausgebreitet wurde, beendet. Nach der Schrotung des Malzes wurde in den Biergefäßen eingemaischt. Die Fermentation konnte zeitgleich auf heterogene Art erfolgen, wobei eine gezielte Wiederverwendung der Hefe am wahrscheinlichsten ist.

Die so rekonstruierten Vorgänge lassen verstehen, warum das große Gefäß im Wohnraum des Erdgeschosses stets an dem am besten belüfteten Platz fest installiert war: die Geruchsentwicklung beim Brauvorgang und besonders die $\mathrm{CO}_{2}$-Entwicklung wurde offensichtlich schon in der Antike als störend empfunden. Wenn also in Bazi jeder Haushalt sein eigenes Bier braute, wie wir aufgrund von keilschriftlichen Informationen seit langem annehmen, müsste sich dasselbe nicht auch in anderen Siedlungen des Alten Orients feststellen lassen?

Unsere bisherigen Untersuchungen sind nur ein kleiner Beitrag im Bemühen um die Rekonstruktion mesopotamischer Bierherstellung. Dennoch stellen die Ergebnisse unser Wissen auf eine ganz neue Basis, von der aus nun in alle Richtungen weiter geforscht werden muss.

Anschrift der Verfasser: Martin Zarnkow, Elmar Spieleder, Werner Back, Technische Universität München, Lehrstuhl für Technologie der Brauerei I, Weihenstephaner Steig 20, 85354 Freising; Bertram Sacher, Doemens e.V., Stefanusstrasse 8, 82166 Gräfelfing; Adelheid Otto, Berthold Einwag, Ludwig-Maximilians-Universität München, Institut für Vorderasiatische Archäologie, Geschwister-Scholl-Platz 1, 80539 München. 
